\title{
Internet Addiction, Psychological Distress, and Coping Responses Among Adolescents and Adults
}

\author{
Michelle L. McNicol, BPsych(Hons), and Einar B. Thorsteinsson, PhD
}

\begin{abstract}
As Internet use grows, so do the benefits and also the risks. Thus, it is important to identify when individuals' Internet use is problematic. In the present study, 449 participants aged from 16 to 71 years of age were sourced from a wide range of English-speaking Internet forums, including social media and self-help groups. Of these, $68.9 \%$ were classified as nonproblematic users, $24.4 \%$ as problematic users, and $6.7 \%$ as addictive Internet users. High use of discussion forums, high rumination levels, and low levels of self-care were the main contributing factors to Internet addiction (IA) among adolescents. For adults IA was mainly predicted through engagement in online video gaming and sexual activity, low email use, as well as high anxiety and high avoidant coping. Problematic Internet users scored higher on emotion and avoidance coping responses in adults and higher on rumination and lower on self-care in adolescents. Avoidance coping responses mediated the relationship between psychological distress and IA. These findings may assist clinicians with designing interventions to target different factors associated with IA.
\end{abstract}

Keywords: internet addiction, cyberpsychology, coping, distress, compulsive internet use

\section{Introduction}

$\mathbf{T}$ HE LAST DECADE HAS seen a proliferation of people using the Internet worldwide, with almost $47 \%$ predicted to be using the Internet by the end of $2016 .{ }^{1}$ While people could possibly be using the Internet to facilitate and improve their everyday lives and activities, a growing number report negative consequences due to excessive Internet use. This may include a loss of control over Internet use, ${ }^{2}$ social problems caused by a preference for being online, ${ }^{3}$ poor school or work performance due to neglecting activities, ${ }^{4}$ and negative health consequences such as disrupted sleep from spending too much time online. ${ }^{5}$

Internet addiction (IA) has been described as "excessive or poorly controlled preoccupation, urges, or behaviors regarding computer use and internet access that lead to impairment or distress" ${ }^{\prime \prime}$ (p. 353). The IA components model ${ }^{2,7}$ conceptualizes IA and incorporates tolerance, withdrawal, relapse, salience, conflict, and mood modification as core symptom criteria for addictive behavior. ${ }^{2}$ IA requires further research as suggested by Section 3 in the DSM-5 on Internet Gaming Disorder. ${ }^{8}$ Prevalence rates for IA varies between
$0.8 \%$ to $26.7 \%^{9}$ with males generally reporting higher levels of IA than females ${ }^{10}$ and young people reporting higher IA scores than older people. ${ }^{11}$ The high variation in prevalence rates may be due to a lack of standardized measurements, varying cut-off scores identifying addiction, and differences in sampling. ${ }^{2}$ The present study employs standardized measures and examines the addictive potential of online video streaming that previous studies have not included in combination with distress and coping measures.

Affective and anxiety disorders, have been linked to IA. ${ }^{12}$ IA appears to be associated with mental disorders in adolescents ${ }^{11}$ and adults, ${ }^{10,13}$ and with developmental traits. ${ }^{14}$ Comorbid symptoms of anxiety and IA have been found in adolescents ${ }^{3}$ and adults. ${ }^{15}$ Additionally, increased stress levels in adults ${ }^{16}$ and stressful life events in adolescents ${ }^{17}$ have been associated with IA. A study of college students found strong positive correlations between stress, anxiety, and depression and IA. ${ }^{18}$ Thus, IA may be associated with increased levels of psychological distress covering a range of psychological conditions. However, the effects of these factors may be mitigated or augmented by individuals' coping behaviors.

\footnotetext{
Department of Psychology, University of New England, Armidale, Australia.
}

(c) Michelle L. McNicol and Einar B. Thorsteinsson 2017; Published by Mary Ann Liebert, Inc. This article is available under the Creative Commons License CC-BY-NC http://creativecommons.org/licenses/by-nc/4.0. This license permits non-commercial use, distribution and reproduction in any medium, provided the original work is properly cited. Permission only needs to be obtained for commercial use and can be done via RightsLink. 
Internet use can also be viewed as a coping response to emotional or social difficulties. ${ }^{19}$ When Internet activities are used excessively to cope with negative affective states (e.g., depression or anxiety), and alternate means of coping responses are diminished (e.g., social support, health promoting behaviour), individuals may find themselves relying on online activities to avoid negative feelings, possibly leading to IA. ${ }^{20}$ Furthermore, coping responses affect the well-being and psychopathology ${ }^{21}$ and could be a risk factor for IA. ${ }^{20}$ IA may occur when Internet activities are used to cope with negative affect. ${ }^{22}$ Thus coping style and cognitive expectations may mediate the symptoms of IA in adults when risk factors such as depression or social anxiety are present. ${ }^{23}$ Individuals with a maladaptive coping style (i.e., avoidance), and who expect to use the Internet to modify their mood, may be more likely to develop IA. ${ }^{23}$ Problematic Internet users are more likely to use avoidance and emotionfocused coping responses than regular Internet users, and are less likely to use adaptive problem-focused coping responses, with strong positive correlations between IA and avoidance coping found in adult college students. ${ }^{24}$ Studies of coping response and IA in adolescence are limited; however, the maladaptive coping response of rumination and acting out are reported to be associated with increased depression levels. $^{25}$

In the current study, it was hypothesized that: (a) depression, anxiety, stress, and maladaptive coping would be positively associated with IA; (b) mental health and coping along with more frequent use of online video gaming, and use of Internet applications such as social networking sites would predict IA levels; (c) "problematic Internet users" would show higher levels of maladaptive coping responses than "regular Internet users"; and (d) in adults, avoidance coping would mediate the relationships between (i) depression and IA, and (ii) anxiety and IA.

\section{Method}

\section{Participants}

An international sample of 628 participants responded to the study, with 497 (79.1\%) participants providing usable data (demographics minimum), whereas 449 (71.5\%) provided more than the minimum usable data needed for hypothesis testing; power $>0.80$. Participants were sourced

Table 1. Participant Characteristics by Internet Use Category

\begin{tabular}{|c|c|c|c|c|c|c|}
\hline \multirow{2}{*}{ Variables } & \multicolumn{2}{|c|}{ Nonproblematic } & \multicolumn{2}{|c|}{ Problematic } & \multicolumn{2}{|c|}{ Addicted } \\
\hline & $\mathrm{n}$ & $\%$ & $\mathrm{n}$ & $\%$ & $\mathrm{n}$ & $\%$ \\
\hline \multicolumn{7}{|l|}{ Sex } \\
\hline Male & 103 & 34.7 & 40 & 38.5 & 9 & 31.0 \\
\hline Female & 192 & 64.6 & 64 & 61.5 & 20 & 69.0 \\
\hline \multicolumn{7}{|l|}{ Age (years) } \\
\hline $16-19$ & 96 & 32.4 & 50 & 47.6 & 12 & 41.4 \\
\hline $20-30$ & 86 & 29.0 & 43 & 41.0 & 12 & 41.4 \\
\hline $31-40$ & 38 & 12.8 & 6 & 5.7 & 2 & 6.9 \\
\hline $41-50$ & 44 & 14.8 & 4 & 3.8 & 0 & 0.0 \\
\hline $51-60$ & 21 & 7.1 & 1 & 1.0 & 3 & 10.3 \\
\hline $61-70$ & 9 & 3.0 & 0 & 0.0 & 0 & 0.0 \\
\hline $71-80$ & 2 & 0.7 & 1 & 1.0 & 0 & 0.0 \\
\hline \multicolumn{7}{|l|}{ Employment status } \\
\hline Full time & 77 & 25.9 & 10 & 9.5 & 3 & 10.3 \\
\hline Part time & 56 & 18.9 & 18 & 17.1 & 2 & 6.9 \\
\hline Self & 5 & 1.7 & 5 & 4.8 & 0 & 0.0 \\
\hline No employment & 14 & 4.7 & 8 & 7.6 & 2 & 6.9 \\
\hline Illness or disability & 3 & 1.0 & 2 & 1.9 & 1 & 3.4 \\
\hline Caring for family member & 2 & 0.7 & 1 & 1.0 & 0 & 0.0 \\
\hline School & 114 & 38.3 & 60 & 57.1 & 19 & 65.5 \\
\hline Other & 26 & 8.8 & 1 & 1.0 & 2 & 6.9 \\
\hline \multicolumn{7}{|l|}{ Living with } \\
\hline Partner & 93 & 31.3 & 16 & 15.2 & 4 & 13.8 \\
\hline Parents/Guardians & 122 & 41.1 & 55 & 52.4 & 12 & 41.4 \\
\hline Relatives & 1 & 0.3 & 1 & 1.0 & 1 & 3.4 \\
\hline Own children & 14 & 4.7 & 8 & 7.6 & 2 & 6.9 \\
\hline Friend(s) & 23 & 7.7 & 12 & 11.4 & 4 & 13.8 \\
\hline No one & 29 & 9.8 & 9 & 8.6 & 2 & 6.9 \\
\hline Other & 15 & 5.1 & 4 & 3.8 & 4 & 13.8 \\
\hline \multicolumn{7}{|l|}{ Education level achieved } \\
\hline Still at secondary school & 40 & 13.5 & 18 & 17.1 & 6 & 20.7 \\
\hline Year 10 or below & 15 & 5.1 & 9 & 8.6 & 2 & 6.9 \\
\hline Year 12 & 66 & 22.2 & 36 & 34.3 & 8 & 27.6 \\
\hline TAFE & 43 & 14.5 & 12 & 11.4 & 3 & 10.3 \\
\hline Undergraduate & 84 & 28.3 & 24 & 22.9 & 6 & 20.7 \\
\hline Postgraduate & 49 & 16.5 & 6 & 5.7 & 4 & 13.8 \\
\hline
\end{tabular}


using various English-speaking outlets on the Internet such as social media, self-help groups, and psychology research pages. Of these $449,64.1 \%$ were female and $35.9 \%$ male, ranging in age from 16 to 71 years of age $(M=27.93$, $S D=13.22$ ). Two subgroups based on age consisted of 163 adolescents (aged 16-19 years), and 285 adults (aged 20-71 years), with one missing value. The majority (51.0\%) of the 449 participants reported their place of residence as North America (USA or Canada) followed by Australia or New Zealand $(39.9 \%)$, Asia (4.5\%), and Europe (4.7\%). Participants were classified into nonproblematic, problematic, and addictive Internet users according to cut-off scores from the Assessment of Internet and Computer Game Addiction (AICA). The majority of participants were nonproblematic. Table 1 shows the demographic profiles of the three groups.

\section{Measures}

The online self-report questionnaire contained 110 questions for participants aged 16-19 years (adolescents), and 136 questions for participants aged 20 years and older. The questionnaire targeted participant demographics, Internet use, IA, depression, anxiety, stress, and coping methods.

Internet use and IA. The Assessment of Internet and Computer Game Addiction Screener (AICA-S) ${ }^{20}$ was used to assess IA. The AICA-S is a 16-item self-report questionnaire adapted from criteria for Substance-Related Disorders. ${ }^{26}$ The AICA-S includes questions about Internet access, frequency, and duration of leisure time Internet use. Participants were asked to rate how often they used 10 different Internet activities (e.g., video games, social networking, discussion forums) on a 5-point Likert scale 0 (Never) to 4 (Very often). The addictive criterion was assessed by asking participants questions about the six core criteria of loss of control, mood modification, relapse, tolerance, preoccupation, and withdrawal symptoms associated with Internet use, (e.g., How often do you avoid negative feelings by spending time using Internet activities?). Responses are used to calculate an IA score ranging from 0 to 27 points. Cut-off scores are categorized into regular use based on 6.5 points or less, problematic use based on 7 points or more, plus 3-4 core criteria fulfilled, and addictive use based on 13.5 points or more, plus 5-6 core criteria fulfilled. ${ }^{20}$ The AICA-S has shown reliable and valid psychometric qualities in epidemiological studies ${ }^{20}$ and clinical samples with diagnostic accuracy in treatment seekers for IA. ${ }^{10}$ Cronbach's alpha for the present study was excellent, $\alpha=0.87$.

Psychological distress. The Depression, Anxiety, and Stress Scale (DASS-21), ${ }^{27}$ was used to assess depression (seven-items: e.g., I felt that I had nothing to look forward to), anxiety (seven-items: e.g., I felt scared without any good reason), and stress (seven-items: e.g., I tended to over-react to situations). Participants were asked to rate the amount they had experienced each item in the past week on a 4-point Likert scale ranging from 0 (Did not apply to me) to 3 ( $\mathrm{Ap}$ plied to me very much, or most of the time). Scores on each subscale are summed, ranging from 0 to 21 , with higher scores indicating higher levels of symptom severity. The DASS-21 is reported to have adequate validity. ${ }^{28}$ Cronbach's alpha for the present study was excellent: depression 0.92 , anxiety 0.89 , and stress 0.89 .

Coping strategies. The Measure of Adolescent Coping Strategies (MACS) ${ }^{29}$ was used to measure coping responses in participants aged 16-19 years. The MACS consists of 34 items with two dimensions: (1) maladaptive coping responses (acting out and rumination, e.g., I had negative thoughts about myself) and (2) adaptive coping responses (stoicism, seeking social support, and self-care, e.g., I tried to look after myself by getting plenty of sleep). Participants were asked to think about how they cope in difficult or stressful situations, and to rate whether they use each strategy on a 4-point Likert scale from 0 (I did not use) to 3 (I used

Table 2. Correlation Matrix of Key Variables for the Adolescent Sample

\begin{tabular}{|c|c|c|c|c|c|c|c|c|c|c|c|}
\hline Measure & 1 & 2 & 3 & 4 & 5 & 6 & 7 & 8 & 9 & 10 & 11 \\
\hline 1. Internet addiction & - & & & & & & & & & & \\
\hline 2. Depression & $0.26 * *$ & - & & & & & & & & & \\
\hline 3. Anxiety & $0.30 * *$ & $0.78 * *$ & - & & & & & & & & \\
\hline 4. Stress & $0.29 * *$ & $0.77 * *$ & $0.82 * *$ & - & & & & & & & \\
\hline 5. Rumination & $0.39 * *$ & $0.52 * *$ & $0.52 * *$ & $0.62 * *$ & - & & & & & & \\
\hline 6. Acting out & $0.19 *$ & $0.55 * *$ & $0.63 * *$ & $0.56 * *$ & $0.37 * *$ & - & & & & & \\
\hline 7. Self-care & $-0.28 * *$ & -0.14 & -0.01 & -0.08 & -0.01 & 0.06 & - & & & & \\
\hline $\begin{array}{l}\text { 8. Seeking social } \\
\text { support }\end{array}$ & -0.05 & -0.03 & 0.06 & 0.04 & $0.23 * *$ & 0.12 & $0.51 * *$ & - & & & \\
\hline $\begin{array}{l}\text { 9. Distraction/ } \\
\text { Stoicism }\end{array}$ & 0.06 & -0.02 & 0.09 & 0.00 & $0.27 * *$ & 0.14 & $0.46 * *$ & $0.49 * *$ & - & & \\
\hline 10. Age & -0.08 & -0.01 & 0.06 & 0.06 & -0.07 & -0.11 & 0.10 & 0.06 & -0.01 & - & \\
\hline 11. Sex & 0.14 & $0.23 * *$ & $0.28 * *$ & $0.35 * *$ & $0.27 * *$ & 0.13 & -0.04 & 0.03 & -0.04 & $0.18^{*}$ & - \\
\hline$M$ & 6.54 & 6.59 & 5.24 & 6.59 & 1.45 & 0.55 & 1.11 & 1.34 & 1.44 & 17.46 & NA \\
\hline$S D$ & 3.98 & 6.00 & 5.01 & 5.15 & 0.73 & 0.59 & 0.66 & 0.67 & 0.58 & 1.08 & NA \\
\hline$N$ & 158 & 138 & 138 & 138 & 149 & 149 & 149 & 149 & 149 & 181 & 178 \\
\hline Actual (min-max) & $0-20$ & $0-21$ & $0-21$ & $0-21$ & $0-3$ & $0-3$ & $0-3$ & $0-3$ & $0-3$ & $16-19$ & $1-2$ \\
\hline Potential (min-max) & $0-27$ & $0-21$ & $0-21$ & $0-21$ & $0-3$ & $0-3$ & $0-3$ & $0-3$ & $0-3$ & $16-19$ & $1-2$ \\
\hline
\end{tabular}

Depression, anxiety, and stress from DASS21. Sex coded as: $1=$ male and $2=$ female.

$* p<0.05$, two-tailed.

$* * p<0.01$, two-tailed. 
Table 3. Correlation Matrix of Key Variables for the Adult Sample

\begin{tabular}{|c|c|c|c|c|c|c|c|c|c|c|}
\hline Measure & 1 & 2 & 3 & 4 & 5 & 6 & 7 & 8 & 9 & 10 \\
\hline 1. Internet addiction & - & & & & & & & & & \\
\hline 2. Depression & $0.52 * *$ & - & & & & & & & & \\
\hline 3. Anxiety & $0.57 * *$ & $0.74 * *$ & - & & & & & & & \\
\hline 4. Stress & $0.46 * *$ & $0.75^{* *}$ & $0.70 * *$ & - & & & & & & \\
\hline 5. Avoidant coping & $0.45^{* *}$ & $0.36 * *$ & $0.39 * *$ & $0.29 * *$ & - & & & & & \\
\hline 6. Emotional coping & $0.51 * *$ & $0.67 * *$ & $0.52 * *$ & $0.61 * *$ & $0.64 * *$ & - & & & & \\
\hline 7. Rational coping & $-0.23 * *$ & $-0.39 * *$ & $-0.36 * *$ & $-0.31 * *$ & -0.03 & $-0.29 * *$ & - & & & \\
\hline 8. Detached coping & $-0.19 * *$ & $-0.35 * *$ & $-0.25 * *$ & $-0.35 * *$ & 0.12 & $-0.30 * *$ & $0.77 * *$ & - & & \\
\hline 9. Age & $-0.26 * *$ & $-0.18 * *$ & $-0.34 * *$ & $-0.25 * *$ & $-0.18 * *$ & $-0.21 * *$ & $0.14^{*}$ & 0.12 & - & \\
\hline 10. Sex & -0.10 & -0.01 & -0.04 & 0.07 & -0.07 & 0.10 & -0.08 & $-0.14^{*}$ & $0.13 *$ & - \\
\hline$M$ & 5.55 & 4.62 & 3.54 & 6.03 & 15.30 & 16.78 & 26.00 & 18.57 & 34.11 & na \\
\hline$S D$ & 4.12 & 5.02 & 4.51 & 4.84 & 5.85 & 8.10 & 8.20 & 7.08 & 13.36 & na \\
\hline$n$ & 272 & 246 & 246 & 246 & 243 & 243 & 243 & 243 & 315 & 315 \\
\hline Actual (min-max) & $0-24$ & $0-21$ & $0-21$ & $0-21$ & $3-36$ & $1-45$ & $2-45$ & $0-43$ & $20-71$ & $1-2$ \\
\hline Potential (min-max) & $0-27$ & $0-21$ & $0-21$ & $0-21$ & $0-39$ & $0-48$ & $0-48$ & $0-45$ & $20+$ & $1-2$ \\
\hline
\end{tabular}

Depression, anxiety, and stress from DASS21. Avoidant coping 13 items. Emotional coping 16 items. Rational coping 16 items. Detached coping 15 items. Sex coded as: $1=$ male and $2=$ female.

$* p<0.05$, two-tailed.

$* * p<0.01$, two-tailed.

almost all the time). The MACS is reported to have adequate construct validity and retest reliability ${ }^{29}$ exceeding that of other adolescent coping scales. ${ }^{30}$ Cronbach's alpha for the current study was acceptable: acting out 0.81 , rumination 0.78 , distraction/stoicism 0.76 , seeking social support 0.83 , and self-care 0.79 .

The Coping Styles Questionnaire (CSQ) ${ }^{21}$ was used to measure coping responses in participants aged over 20 years. The CSQ consists of 60 items with two dimensions: (a) maladaptive coping responses (emotional coping 16 items and avoidance coping 13 items; e.g., Distance myself so I do not have to make any decisions about the situation) and (b) adaptive coping responses (rational 16 items and detached 15 items). Participants were asked to rate how they typically react to stress on a 4-point Likert scale from 0 (Never) to 3 (Always), with higher scores indicating higher levels of the coping response. The CSQ is reported to have adequate construct validity and retest reliability. ${ }^{21}$ Cronbach's alpha for the present study was good: avoidance coping 0.81 , emotional coping 0.91 , rational coping 0.91 , and detached coping .88 .

\section{Procedure}

Approval to conduct the study was granted from the University of New England's (UNE) Human Research Committee (HE14-127). Participants were recruited through

Table 4. Predicting Adolescents' Internet Addiction $(N=135)$

\begin{tabular}{|c|c|c|c|c|c|c|}
\hline \multirow[b]{2}{*}{ Predictor } & \multirow[b]{2}{*}{$B$} & \multicolumn{2}{|c|}{$95 \%$ CI for $b$} & \multirow[b]{2}{*}{$\beta$} & \multirow[b]{2}{*}{$\mathrm{R}$} & \multirow[b]{2}{*}{$s r^{2}$} \\
\hline & & Lower & Upper & & & \\
\hline Video gaming & 0.33 & -0.18 & 0.84 & 0.12 & 0.19 & 0.01 \\
\hline Social networking & -0.12 & -0.66 & 0.43 & -0.04 & 0.17 & 0.00 \\
\hline Web browsing & -0.11 & -0.78 & 0.57 & -0.03 & 0.20 & 0.00 \\
\hline Video streaming & 0.46 & -0.19 & 1.10 & 0.13 & 0.29 & 0.02 \\
\hline Shopping & -0.14 & -0.77 & 0.50 & -0.04 & 0.03 & 0.00 \\
\hline Sexual activity & 0.48 & -0.10 & 1.05 & 0.15 & 0.14 & 0.02 \\
\hline Gambling & -0.53 & -1.52 & 0.45 & -0.10 & -0.03 & 0.01 \\
\hline Email & 0.35 & -0.31 & 1.02 & 0.10 & 0.22 & 0.01 \\
\hline Discussion forums & 0.76 & 0.15 & 1.37 & 0.22 & 0.26 & 0.05 \\
\hline Instant messaging & 0.17 & -0.32 & 0.65 & 0.06 & 0.22 & 0.00 \\
\hline Depression & -0.05 & -0.23 & 0.14 & -0.07 & 0.27 & 0.00 \\
\hline Anxiety & 0.20 & -0.05 & 0.46 & 0.25 & 0.30 & 0.02 \\
\hline Stress & -0.13 & -0.37 & 0.12 & -0.16 & 0.30 & 0.01 \\
\hline Rumination & 1.48 & 0.20 & 2.75 & 0.26 & 0.38 & 0.04 \\
\hline Acting out & 0.41 & -1.12 & 1.94 & 0.06 & 0.23 & 0.00 \\
\hline Self-care & -1.61 & -2.76 & -0.45 & -0.27 & -0.28 & 0.06 \\
\hline Seeking social support & -0.35 & -1.48 & 0.78 & -0.06 & -0.05 & 0.00 \\
\hline Stoicism & 0.70 & -0.65 & 2.06 & 0.10 & 0.06 & 0.01 \\
\hline Age & -0.33 & -0.95 & 0.29 & -0.09 & -0.11 & 0.01 \\
\hline Sex & 1.25 & -0.42 & 2.93 & 0.15 & 0.14 & 0.02 \\
\hline
\end{tabular}

Fit for model $R^{2}=0.40$, Adjusted $R^{2}=0.29, F(20,114)=3.77, p<0.001$. The squared semi-partial $\left(s r^{2}\right)$ correlation given is the squared Part correlation from SPSS. The $r$ given is for the zero-order correlation from SPSS. Sex: $1=$ Male, $2=$ Female. Bold $=$ where CI did not include a zero. 
Table 5. Predicting Adults' Internet Addiction $(N=241)$

\begin{tabular}{|c|c|c|c|c|c|c|}
\hline \multirow[b]{2}{*}{ Predictor } & \multirow[b]{2}{*}{$B$} & \multicolumn{2}{|c|}{$95 \% C I$ for $b$} & \multirow[b]{2}{*}{$\beta$} & \multirow[b]{2}{*}{$R$} & \multirow[b]{2}{*}{$s r^{2}$} \\
\hline & & Lower & Upper & & & \\
\hline Video gaming & 0.42 & 0.08 & 0.77 & 0.13 & 0.31 & $\mathbf{0 . 0 3}$ \\
\hline Social networking & 0.18 & -0.19 & 0.54 & 0.05 & 0.07 & 0.00 \\
\hline Web browsing & 0.08 & -0.48 & 0.65 & 0.02 & 0.09 & 0.00 \\
\hline Video streaming & 0.30 & -0.14 & 0.74 & 0.08 & 0.33 & 0.01 \\
\hline Shopping & -0.02 & -0.46 & 0.41 & -0.01 & 0.16 & 0.00 \\
\hline Sexual activity & 0.64 & 0.21 & 1.07 & 0.18 & 0.34 & 0.04 \\
\hline Gambling & -0.31 & -1.03 & 0.41 & -0.04 & 0.07 & 0.00 \\
\hline Email & -0.50 & -0.97 & -0.03 & -0.12 & -0.08 & 0.02 \\
\hline Discussion forums & 0.21 & -0.17 & 0.59 & 0.06 & 0.26 & 0.01 \\
\hline Instant messaging & 0.13 & -0.23 & 0.48 & 0.04 & 0.23 & 0.00 \\
\hline Depression & 0.00 & -0.15 & 0.16 & 0.00 & 0.53 & 0.00 \\
\hline Anxiety & 0.26 & 0.11 & 0.41 & 0.28 & 0.58 & $\mathbf{0 . 0 5}$ \\
\hline Stress & 0.05 & -0.09 & 0.19 & 0.06 & 0.48 & 0.00 \\
\hline Avoidant coping & 0.12 & 0.02 & 0.23 & 0.17 & 0.46 & $\mathbf{0 . 0 2}$ \\
\hline Emotional coping & 0.07 & -0.02 & 0.16 & 0.13 & 0.51 & 0.01 \\
\hline Rational coping & 0.02 & -0.07 & 0.10 & 0.03 & -0.23 & 0.00 \\
\hline Detached coping & -0.08 & -0.18 & 0.03 & -0.13 & -0.19 & 0.01 \\
\hline Age & 0.01 & -0.03 & 0.04 & 0.02 & -0.27 & 0.00 \\
\hline Sex & 0.15 & -0.94 & 1.23 & 0.02 & -0.13 & 0.00 \\
\hline
\end{tabular}

Fit for model $R^{2}=0.51$, Adjusted $R^{2}=0.47, F(19,221)=12.26, p<0.001$. The squared semi-partial $\left(s r^{2}\right)$ correlation given is the squared Part correlation from SPSS. The $r$ given is for the zero-order correlation from SPSS. Sex: $1=$ Male, $2=$ Female. Bold $=$ where CI did not include a zero.

English-speaking Internet forums (e.g., www.gamespot. com), IA self-help groups (e.g., www.olganon.org), psychological research pages (e.g., www.socialpsychology.org), and social media (e.g., www.facebook.com). UNE first- and fourth-year psychology students were recruited through the online learning platform Moodle, with course credit being awarded to first-year psychology participants.

The study was conducted using Qualtrics Survey Software (Qualtrics, Provo, UT), with participants directed, through an online link, to the website. An information sheet informed participants that their responses were anonymous and confidential, and that they could withdraw from the study at any time. Participants proceeded to the study by clicking on the Yes, I consent to participate icon. Participants who selected aged under 16 were automatically exited from the study, as participation required individuals to be 16 years of age or older. Participants who completed the study were invited to enter a prize draw to win one of three $\$ 50$ vouchers, by providing their email details in a separate survey listing.

\section{Statistical analyses}

Data were analyzed using SPSS (version 22). The online survey had 628 responses, but given lack of consent $(n=44)$, underage $(n=8$, directed elsewhere), withdrawal $(n=9)$, lack of answers $(n=53)$, duplicates $(n=16)$, and nonsense answers $(n=1)$, there remained 497 participants of which 48 gave only the most basic answers, leaving 449. Mediation analyses were conducted using a SPSS macro PROCESS (v2.15) Model 4, with 5000 bootstrap samples, bias-corrected and accelerated (BCa), and 95\% confidence intervals. ${ }^{31}$ Kappa squared $\left(k^{2}\right)$ is reported as the measure of mediation effect size, and is the proportion of the maximum possible indirect effect. ${ }^{32}$

\section{Results}

\section{Demographics}

An independent samples $t$-test was used to explore the difference in AICA-S scores between males and females, and between adolescents and adults. No significant difference in IA scores was found between males and females, $t(426)=0.42, p=0.679$ (two-tailed). However, age was significantly associated with IA, $r(428)=-0.24, p<0.001$ (twotailed), with the higher the age the lower the IA, but this was mainly true for the adult sample only (Tables 2 and 3). Participants reported using a range of different Internet activities often or very often, such as web browsing (77.5\%),

Table 6. Group Differences Means (SD) in Internet Addiction and Coping Response in Adolescents

\begin{tabular}{lccc}
\hline Variable & Nonproblematic $(\mathrm{n}=90)$ & Problematic and Addicted $(\mathrm{n}=59)$ & Hedges' $g$ [95\% CI] \\
\hline Rumination & $1.28(0.68)$ & $1.71(0.72)$ & $0.61[0.28,0.95]$ \\
Acting out & $0.51(0.58)$ & $0.62(0.60)$ & $0.19[-0.14,0.52]$ \\
Self-care & $1.24(0.65)$ & $0.90(0.63)$ & $0.53[0.19,0.86]$ \\
Distraction/Stoicism & $1.42(0.57)$ & $1.47(0.59)$ & $0.09[-0.24,0.41]$ \\
Seeking social support & $1.38(0.62)$ & $1.28(0.73)$ & $0.15[-0.18,0.48]$ \\
\hline
\end{tabular}


Table 7. Group Differences in Internet AdDiction and Coping Response in Adults

\begin{tabular}{lccc}
\hline Coping & Nonproblematic $(\mathrm{n}=176)$ & Problematic and Addicted $(\mathrm{n}=67)$ & Hedges' $\mathrm{g}$ [95\% CI] \\
\hline Avoidance & $14.05(5.13)$ & $18.60(6.36)$ & $0.83[0.53,1.12]$ \\
Emotional & $14.94(6.73)$ & $21.60(9.36)$ & $0.88[0.59,1.17]$ \\
Detached & $26.84(7.92)$ & $23.82(8.56)$ & $0.37[0.09,0.65]$ \\
Rational & $19.06(6.87)$ & $17.28(7.51)$ & $0.25[-0.03,0.53]$ \\
\hline
\end{tabular}

social networking sites $(73.0 \%)$, email $(55.9 \%)$, video streaming content $(56.2 \%)$, shopping (30.3\%), instant messaging (35.4\%), video gaming (19.8\%), discussion forums (13.4\%), sexual activity (11.3\%), and gambling (2.0\%).

\section{Psychological distress, coping response, and IA}

Hypothesis 1 was supported. IA scores were positively correlated with depression, anxiety, and stress in adolescents (Table 2) and adults (Table 3). Maladaptive coping responses of emotional and avoidance coping in adults, rumination, and acting out in adolescents were positively correlated with IA. Adaptive coping responses of rational and detached coping in adults, and self-care in adolescents were negatively correlated with IA.

\section{Predictors of IA}

To estimate the proportion of variance in IA accounted for by mental health, coping, and different Internet activities used (Hypothesis 2), multiple regression analyses were conducted. For adolescents, Internet activities accounted for $29.2 \%$ of the variance in IA ( $R^{2}$ adjusted $), F(20,114)=3.77$, $p<0.001$, with high discussion forum use, high rumination, and low self-care being the strongest predictors of IA (Table 4). For adults, the key predictors of IA were high use of video gaming and sexual Internet activity, low use of email, and high anxiety and avoidant coping levels. Adjusted $R^{2}=0.47, F(19,221)=12.26, p<0.001$ (Table 5).

\section{Coping responses in nonproblematic} and problematic internet users

Internet user groups were compared in relation to coping methods (Hypothesis 3). Adolescents in the nonproblem Internet user group had lower rumination and higher selfcare than adolescents in the problematic and addicted group (Table 6). Adult nonproblematic Internet users used less avoidance and emotional coping and more detached and rational coping than their problematic/addicted counterparts (Table 7).

\section{Mediation of avoidance coping}

Testing Hypothesis 4, we found that for the adult participants, avoidance coping mediated the relationship between depression and IA, indirect effect, $R^{2}=0.13$ [0.06, 0.23], $k^{2}=0.12,95 \%$ BCa $[0.06,0.20]$ (Fig. 1). Avoidance coping mediated the relationship between anxiety and IA, indirect effect, $R^{2}=0.15[0.07,0.24], k^{2}=0.12,95 \% \mathrm{BCa}[0.06,0.19]$ (Fig. 2).

\section{Discussion}

IA was not found to be different between males and females suggesting that with increased Internet availability, and thus use, sex differences are being reduced. In the adult sample, the lower the age the higher the IA. This association may disappear as the young adults get more mature and take with them both the negative and positive aspects of Internet use. Affective disorders and coping seem to play an important role in IA among adolescents and adults. Internet activities within the adult sample, such as video gaming and sexual activity, and within the adolescent sample, such as discussion forum use predict higher IA, thus partly supporting previous findings ${ }^{10,33}$ suggesting that interventions need to focus on these particular activities to reduce IA. The results showing different predictors of IA for different age groups suggest that a combination of online activities is important: for example, individuals who play online video games will clearly also be more likely to participate in forums discussing aspects of video games. IA was also associated with increased levels of psychological distress, supporting previous findings regarding the relationship between IA and depression and other comorbid disorders. ${ }^{10,11,17}$ Furthermore, increased IA was

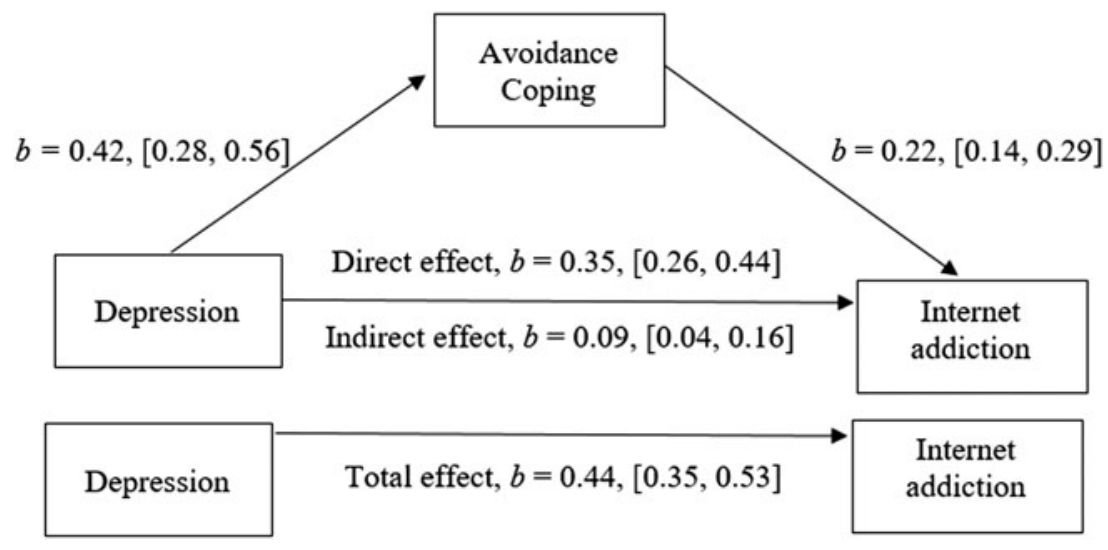

FIG. 1. Mediation by avoidance coping on the depression-Internet addiction relationship $(N=241)$. 
FIG. 2. Mediation by avoidance coping on the anxiety-Internet addiction relationship $(N=241)$.

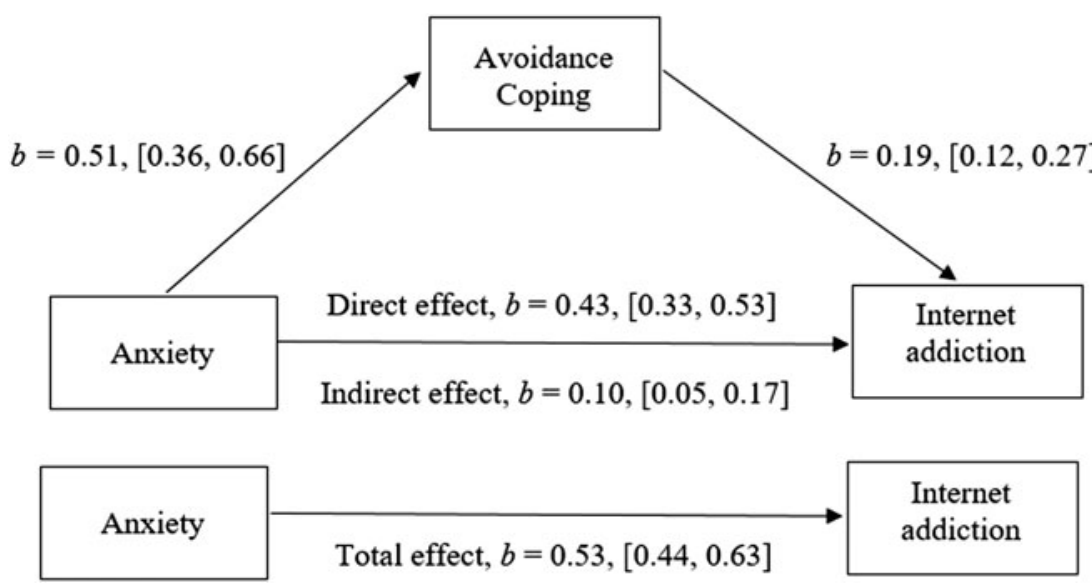

associated with increased maladaptive coping and decreased adaptive coping in both adolescents and adults. This suggests that coping may play an important role in any IA interventions and any modeling of IA as shown by the mediation models in which avoidance coping mediated the effects of depression and anxiety on IA in adults.

Adolescents in the nonproblem Internet group seem to benefit from employing coping such as high self-care and low rumination. This supports previous findings for adolescents that have found rumination to be associated with increased distress and less satisfaction with life, ${ }^{34}$ and where rumination has mediated the effects of stress on depression. ${ }^{35}$ Adults in the nonproblem Internet group benefitted from coping that was less avoidant and emotional and was instead more detached and rational suggesting that avoidance coping (e.g., Internet distractions) may play a part in a high IA score, while detached and rational coping may enable the individual to rationally limit their Internet use.

Similar to the participants in the present study, individuals dealing with gambling ${ }^{36}$ and substance use issues ${ }^{37}$ have been found to use maladaptive coping (e.g., avoidance, anger) and to suffer from depression and anxiety. Thus, it is possible that IA may share comorbid factors with other behavioral addictions. Therefore, IA may be an end-point caused by underlying factors such as maladaptive coping, negative personality profile, ${ }^{38,39}$ lower emotional intelligence, ${ }^{40}$ and implicit cognition. ${ }^{41}$ Alcohol use has also been linked with future psychiatric disorders, ${ }^{42}$ suggesting that if IA is an end-point like other behavioral addictions, then it may have similar outcomes such as major depression.

\section{Future Studies and Limitations}

The findings of the current study suggest that any future interventions or research need to consider many different aspects when examining IA, including coping and psychological distress. Given that short Internet-based interventions have been found to be effective when treating substance userelated problems, ${ }^{43}$ Internet based treatments may also be useful for Internet-based issues. Given the importance of good communication and liking school in reducing the risk of suicidal ideations and attempts, ${ }^{44}$ it is important to incorporate family, peer, and school interactions into future studies and interventions.
The present study has some limitations. First, the crosssectional design means it is not possible to draw causal inferences from the data and mediation models are only hypothetical. ${ }^{45}$ Second, there is a lack of generalizability of current research findings. The online convenience sample of Internet users may not represent the general population of Internet users or those with IA. Sampling may also have caused bias in attracting or repelling participants with IA. Third, self-report measures only indicate IA; they cannot diagnose IA. Fourth, the study is limited in its ability to compare adults versus adolescents due to the limited sample size for the adolescent group. That said, the strength of the study was the support for the role of maladaptive coping established using two independent, age-appropriate measures.

\section{Conclusion}

The results of this study highlight the importance of clinical awareness of the symptoms of IA. As computer and Internet use is now an integral part of work and education, clinicians need to identify the signs of problematic Internet use and differentiate between IA, other comorbid mental disorders, and appropriate Internet use. ${ }^{5}$ Early intervention and identification of those showing signs of problematic Internet use may prevent the development of maladaptive coping responses and addictive behavior, thus preventing future negative psychosocial consequences. ${ }^{46}$ The results of this study may assist clinicians with designing cognitive behavioral interventions and prevention programs targeting maladaptive coping.

\section{Funding}

This research did not receive any specific grant from funding agencies in the public, commercial, or not-for-profit sectors.

\section{Acknowledgments}

The authors would like to thank Dr. Philip Tam, Network for Internet Investigation and Research in Australia and the University of Sydney, and Dr. Natasha Loi, University of New England, Australia. 


\section{Author Disclosure Statement}

No competing financial interests exist.

\section{References}

1. ICT Data and Statistics Division. (2016) ICT facts and figures 2016. Geneva, Switzerland: ICT Data and Statistics Division.

2. Kuss DJ, Shorter GW, van Rooij AJ, et al. Assessing internet addiction using the parsimonious internet addiction components model - a preliminary study. International Journal of Mental Health and Addiction 2014; 12:351-366.

3. King DL, Delfabbro PH, Zwaans T, Kaptsis D. Clinical features and axis I comorbidity of Australian adolescent pathological Internet and video game users. Australian and New Zealand Journal of Psychiatry 2013; 47:1058-1067.

4. Kirschner PA, Karpinski AC. Facebook ${ }^{\circledR}$ and academic performance. Computers in Human Behavior 2010; 26: 1237-1245.

5. Young K. Internet addiction: diagnosis and treatment considerations. Journal of Contemporary Psychotherapy 2009; 39:241-246.

6. Shaw M, Black DW. Internet addiction. CNS Drugs 2008; 22:353-365.

7. Griffiths M. A 'components' model of addiction within a biopsychosocial framework. Journal of Substance Use 2005; 10:191-197.

8. Petry NM, O'Brien CP. Internet gaming disorder and the DSM-5. Addiction 2013; 108:1186-1187.

9. Kuss DJ, Griffiths MD, Karila L, Billieux J. Internet addiction: a systematic review of epidemiological research for the last decade. Current Pharmaceutical Design 2014; 20 : 4026-4052.

10. Müller KW, Beutel ME, Wölfling K. A contribution to the clinical characterization of Internet addiction in a sample of treatment seekers: validity of assessment, severity of psychopathology and type of co-morbidity. Comprehensive Psychiatry 2014; 55:770-777.

11. Morrison CM, Gore H. The relationship between excessive Internet use and depression: a questionnaire-based study of 1,319 young people and adults. Psychopathology 2010; 43:121-126.

12. Weinstein A, Lejoyeux M. Internet addiction or excessive internet use. The American Journal of Drug and Alcohol Abuse 2010; 36:277-283.

13. Young KS, Rodgers RC. The relationship between depression and Internet addiction. CyberPsychology \& Behavior 1998; 1:25-28.

14. Romano M, Osborne LA, Truzoli R, et al. Differential psychological impact of internet exposure on internet addicts. PLoS One 2013; 8:e55162.

15. Ko CH, Yen JY, Yen CF, et al. The association between Internet addiction and psychiatric disorder: a review of the literature. European Psychiatry 2012; 27:1-8.

16. Deatherage S, Servaty-Seib HL, Aksoz I. Stress, coping, and internet use of college students. Journal of American College Health 2014; 62:40-46.

17. Leung L. Stressful life events, motives for Internet use, and social support among digital kids. CyberPsychology \& Behavior 2006; 10:204-214.

18. Akin A, Iskender $M$. Internet addiction and depression, anxiety and stress. International Online Journal of Educational Sciences 2011; 3:138-148.
19. Bernardi S, Pallanti S. Internet addiction: a descriptive clinical study focusing on comorbidities and dissociative symptoms. Comprehensive Psychiatry 2009; 50:510-516.

20. Müller KW, Glaesmer H, Brähler E, et al. Prevalence of Internet addiction in the general population: results from a German population-based survey. Behaviour \& Information Technology 2013; 33:757-766.

21. Roger D, Jarvis G, Najarian B. Detachment and coping: the construction and validation of a new scale for measuring coping strategies. Personality and Individual Differences 1993; 15:619-626.

22. Young K. (1998) Caught in the net: How to recognize the signs of Internet addiction: a winning strategy for recovery. New York, NY: John Wiley \& Sons.

23. Brand M, Laier C, Young KS. Internet addiction: coping styles, expectancies, and treatment implications. Frontiers of Physiology 2014; 5:1256.

24. Li D, Zhang W, Li X, et al. Stressful life events and problematic Internet use by adolescent females and males: a mediated moderation model. Computers in Human Behavior 2010; 26:1199-1207.

25. Thorsteinsson EB, Davey L. Adolescents' compulsive Internet use and depression: a longitudinal study. Open Journal of Depression 2014; 3:13-17.

26. American Psychiatric Association. (2005) Diagnostic and Statistical Manual of Mental Disorders, Fourth Edition, Text Revision (DSM-IV-TR). Arlington, VA: American Psychiatric Association.

27. Lovibond SH, Lovibond PF. (1995) Manual for the depression anxiety stress scales. Sydney, NSW, Australia: Psychology Foundation of Australia.

28. Antony MM, Bieling PJ, Cox BJ, et al. Psychometric properties of the 42-item and 21-item versions of the Depression Anxiety Stress Scales in clinical groups and a community sample. Psychological Assessment 1998; 10:176.

29. Sveinbjornsdottir S, Thorsteinsson EB. Psychometric properties of the Measure of Adolescent Coping Strategies (MACS). Psychology 2014; 5:142-147.

30. Sveinbjornsdottir S, Thorsteinsson EB. Adolescent coping scales: a critical psychometric review. Scandinavian Journal of Psychology 2008; 49:533-548.

31. Hayes AF. (2013) Introduction to mediation, moderation and conditional process analysis. New York, NY: Guilford Press.

32. Preacher KJ, Kelley K. Effect size measures for mediation models: quantitative strategies for communicating indirect effects. Psychological Methods 2011; 16:93.

33. Kuss DJ, Griffiths MD, Binder JF. Internet addiction in students: prevalence and risk factors. Computers in Human Behavior 2013; 29:959-966.

34. Thorsteinsson EB, Sveinbjornsdottir S, Dintsi M, et al. Negative life events, distress, and coping among adolescents in Botswana. Australian Journal of Educational \& Developmental Psychology 2013; 13:75-86.

35. Thorsteinsson EB, Ryan S, Sveinbjornsdottir S. The mediating effects of social support and coping on the stressdepression relationship in rural and urban adolescents. Open Journal of Depression 2013; 2:1-6.

36. McCormick RA. The importance of coping skill enhancement in the treatment of the pathological gambler. Journal of Gambling Studies 1994; 10:77-86.

37. Wills TA, Sandy JM, Yaeger AM, et al. Coping dimensions, life stress, and adolescent substance use: a latent 
growth analysis. Journal of Abnormal Psychology 2001; 110:309.

38. Malouff JM, Thorsteinsson EB, Rooke SE, et al. Alcohol involvement and the Five-Factor Model of personality: a meta-analysis. Journal of Drug Education 2007; 37:277294.

39. Kotov R, Gamez W, Schmidt F, et al. Linking "big” personality traits to anxiety, depressive, and substance use disorders: a meta-analysis. Psychological Bulletin 2010; 136:768.

40. Peterson K, Malouff JM, Thorsteinsson EB. A metaanalytic investigation of emotional intelligence and alcohol involvement. Substance Use \& Misuse 2011; 46:17261733.

41. Rooke SE, Hine DW, Thorsteinsson EB. Implicit cognition and substance use: a meta-analysis. Addictive Behaviors 2008; 33:1314-1328.

42. Brook DW, Brook JS, Zhang C, et al. Drug use and the risk of major depressive disorder, alcohol dependence, and substance use disorders. Archives of General Psychiatry 2002; 59:1039-1044.
43. Rooke SE, Thorsteinsson EB, Karpin A, et al. Computer delivered interventions for alcohol and tobacco use: a meta analysis. Addiction 2010; 105:1381-1390.

44. Arnarsson A, Sveinbjornsdottir S, Thorsteinsson EB, et al. Suicidal risk and sexual orientation in adolescence: a population-based study in Iceland. Scandinavian Journal of Public Health 2015; 43:497-505.

45. Maxwell SE, Cole DA. Bias in cross-sectional analyses of longitudinal mediation. Psychological Methods 2007; 12:23-44.

46. Tao R, Huang X, Wang J, et al. Proposed diagnostic criteria for Internet addiction. Addiction 2010; 105:556-564.

Address correspondence to: Dr. Einar B. Thorsteinsson Department of Psychology University of New England Armidale 2351 Australia

E-mail: ethorste@une.edu.au 